\title{
Sphingolipid Metabolism Inhibitors and Cell Function
}

\author{
E. Albi* and M. Viola Magni \\ Department of Clinical and Experimental Medicine, Physiopathology, Policlinico Monteluce, University of Perugia, \\ Italy
}

\begin{abstract}
It has been widely shown that ceramide, ceramide phosphate, sphingosine and sphingosine-1-phosphate are molecules involved in cell proliferation, differentiation and apoptosis. The regulation of the enzymes that control their metabolism has an important role for cellular fate. Many studies in the field have shed light on sphingolipid metabolism inhibition and on its role in cell processes such as gene expression, DNA duplication and RNA transcription. The aim of this review is to collect, in a systematic way, the recent advances in the field of sphingolipid metabolism inhibitors, with special emphasis on their effects on cell function.
\end{abstract}

\section{INTRODUCTION}

The name sphingolipid was born at the end of the XIX century on the basis of the molecule structure similar to the riddle of the sphinx. These molecules are complex lipids, localized in animal and plant membranes and in some forms of lower life, which contain sphingoid bases and have a very complex metabolism.

The sphingolipid biosynthetic pathway initiates with the condensation of the serine with palmitoyl-CoA to form 3ketodihydrosphingosine or 3-ketosphinganine, a serine palmitoyl transferase (SPT) catalyzed reaction. 3-ketodihydrosphingosine is reduced to dehydrosphingosine or sphinganine by a NADPH dependent 3-ketosphinganine reductase. An acylation in the presence of acyl-CoA produces dihydroceramide by ceramide synthase (CerS). Dihydroceramide is then converted to ceramide through the introduction of the double bond trans- $4,-5$ by dihydroceramide desaturase.

The ceramide can be transformed to sphingomyelin (SM) by two different ways: the first one involves the reaction with CDP-choline catalyzed by ceramide choline phosphotransferase and the second, described subsequently, consists in phosphocholine transfer from lecithin to ceramide by phosphatidylcholine: ceramide phosphocholine transferase or sphingomyelin synthase (SM-synthase). The synthesized SM can be used as source of phosphocholine to form phosphatidylcholine in the presence of diacylglycerol by reversesphingomyelin-synthase (RSM-synthase) freeing ceramide, or can be degraded to ceramide and phosphocholine by acid or neutral sphingomyelinase (aSMase or N-SMase). The new-produced ceramide can be deacylated by acid or neutral ceramidase (AC or $\mathrm{NC}$ ) to form sphingosine, which can be phosphorylated by a sphingosine kinase 1 (SphK1) or by sphingosine kinase 2 (SphK2) to sphingosine phosphate, can be phosphorylated by ceramide kinase (CerK) or can be

*Address correspondence to this author at the Department of Clinical and Experimental Medicine, Physiopathology, Policlinico Monteluce, University of Perugia, Italy - Via Brunamonti - 06100 Perugia, Italy; Tel/Fax: +39075-5729085; E-mail: ealbi@unipg.it transformed to glucosylceramide and dihydroglucosylceramide then converted to lactosylceramide and to more complex sphingolipids. Today many inhibitors of the sphingolipid metabolism have been studied (Table 1). They act at different steps reducing the level of molecules involved in signal transduction such as ceramide, ceramide phosphate, sphingosine and sphingosine-1-phosphate

\section{INHIBITORS OF SPHINGOLIPID BIOSYNTHETIC PATHWAY}

\section{Serine Palmitoyl Transferase (SPT)}

The inhibition of SPT, first enzyme of sphingolipid synthesis, is responsible for the reduction either of sphingosine and ceramide or SM. The selective inhibitors of this enzyme are beta-chloroalanine which maintains low sphingosine content for a long time [1] and L-cycloserine which blocks the sphinganine synthesis [2]. Analogs of sphingosine such as cytotoxic cyclic analogs 99 and Z-4-methylsphingosine 2-azidosphingosine [3] interfere with SPT. In addition, SPT is inhibited with natural products [4] as stereoisomers of the antifungal sphingofungin B [5] which act by C-14 hydroxyl group and antifungal antibiotic myriocin [6] which does not need of $\mathrm{C} 4-\mathrm{OH}, \mathrm{C} 6$ double bond and C14-keto groups, as well as $\mathrm{C} 3-\mathrm{OH}$ configuration, for its biological activity [6-8]. Myriocin blocks in this way the ceramide de novo synthesis in Jurkat acute leukemia cells [9] and in particular the formation of long-chain ceramide species which stimulate proteasomal activation with subsequent activation of caspases [10]. Sphinganine and not ceramide analogues, such as $\mathrm{C} 2$ and C6, are not able to reverse the inhibitory effect of myriocin [11]. Reducing the ceramide content, myriocin is responsible for the decrease of SM concentration in the liver [12].

\section{Ceramide-Synthase (CerS)}

Besides SPT inhibitors, ceramide synthesis is also inhibited by molecules which act specifically on $\mathrm{CerS}$ as $\mathrm{Fu}$ monisin B1 and mycotoxin, appertaining to fumonisins family, produced by the fungus Fusarium verticillioides [13]. The specificity of Fumonisin B1 for this enzyme has been demonstrated in LLC-PK1 cells in which the decrease of pERK2 phosphorylation in response to Fumonisin B1 is 
Table 1. Inhibitors of Sphingolipid Metabolism. The Table Lists Inhibitors, Enzyme Inhibited, Cell Type, and References

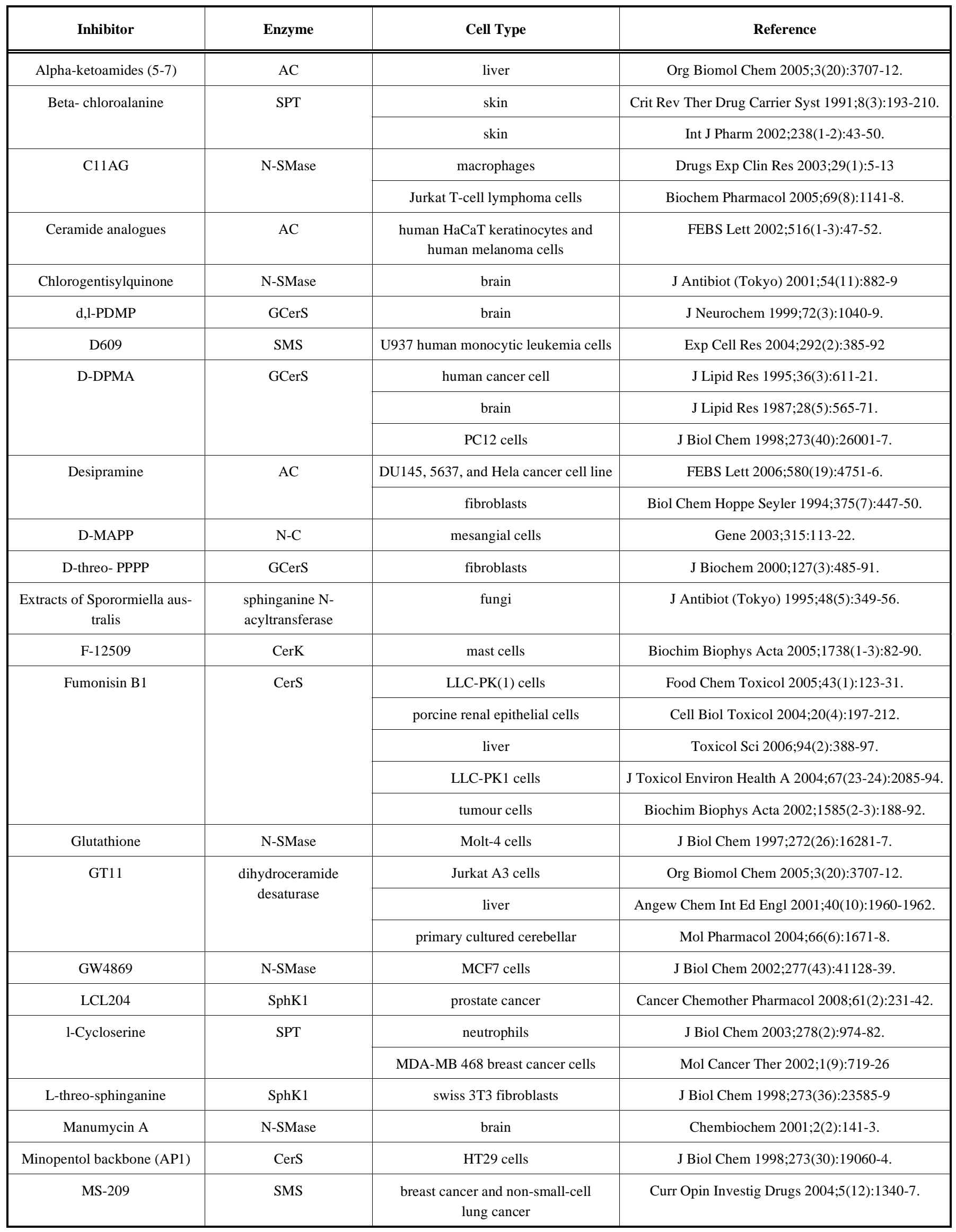


Table 1 Cont...

\begin{tabular}{|c|c|c|c|}
\hline Myriocin & SPT & Jurkat cells & J Biol Chem 2001;276(48):44848-55. \\
\hline Myriocin derivates & SPT & lymphocyte & J Antibiot (Tokyo) 1996;49(9):846-53 \\
\hline ISP-1/Myriocin & SPT & Ramos cells & J Biol Chem 2003;278(17):14723-31. \\
\hline $\begin{array}{l}\mathrm{N}-(\mathrm{n} \text {-butyl) deoxynojirimy- } \\
\text { cin }\end{array}$ & GCerS & GM95 mouse melanoma cells & Faseb J 2003;17(9):1144-6 \\
\hline N,N-dimethylsphingosine & SPHK1 & $\begin{array}{c}\text { human A549 epithelial lung } \\
\text { carcinoma cells }\end{array}$ & Cell Signal 2005;17(10):1203-17. \\
\hline \multirow[t]{2}{*}{ N-butyldeoxynojirimycin } & GCerS & brain & J Neurochem 1999;72(3):1040-9. \\
\hline & $\begin{array}{l}\text { glucosylceramide } \\
\text { transferase }\end{array}$ & brain & Acta Paediatr Suppl 2005;94(447):69-75 \\
\hline N-octyl beta-valienamine & beta-glucocerebrosidase & liver & Bioorg Med Chem 1998;6(10):1955-62 \\
\hline OGT2378 & GcerS & MEB4 melanoma cells & Cancer Res 2003;63(13):3654-8. \\
\hline \multirow[t]{2}{*}{ PDMP and PPPP } & \multirow[t]{2}{*}{ GCerS } & hepatoma cells & Biochem Biophys Res Commun 2001;288(1):269-74. \\
\hline & & KB cell lines & Br J Cancer 1999;81(3):423-30 \\
\hline \multirow[t]{2}{*}{ Scyphostatin } & \multirow[t]{2}{*}{ N-SMase } & endothelial cell & Am J Physiol Heart Circ Physiol 2004;287(3):H1344-52. \\
\hline & & brain & J Antibiot (Tokyo) 1999;52(6):525-30 \\
\hline Scyphostatin analogue & N-SMase & monocytes, macrophages, hepatocytes & Chembiochem 2005;6(4):726-37 \\
\hline \multirow{2}{*}{ SM analogues } & \multirow{2}{*}{ SMase } & Bacillus cereus & Org Lett 2000;2(17):2627-9 \\
\hline & & Bacillus cereus & Org Lett 2003;5(16):2801-4. \\
\hline \multirow[t]{2}{*}{ SR33557 } & \multirow[t]{2}{*}{ A-SMase } & P388/ADR cells & J Biol Chem 1991;266(29):19858-60 \\
\hline & & Rinm5F cells & Autoimmunity 2000;32(4):241-54. \\
\hline XM462 & dihydroceramide desaturase & Jurkat A3 cells & ChemMedChem 2008; 3(6):946-53. \\
\hline
\end{tabular}

independent of sphingosine and ceramide derived from SM and it is due only to the inhibition of de novo ceramide biosynthesis [14]. Curiously, after 5 daily treatment with Fumonisin B1 in mice, the SPT and acid sphingomyelinase (aSMase) activity and sphingoid bases content increase significantly in the liver to maintain a balance of cellular sphingolipids [15]. This effect is specific since another hepatotoxicant, as acetaminophen, induces liver regeneration similar to Fumonisin B1 but does not produce similar effects on liver sphingolipid metabolizing enzymes [16]. Nevertheless it has been shown that Fumonisin B1 enters with difficulty into the cells determining a low inhibitor effect on CerS. The higher effect is obtained by australifungin, a micotoxin iso- lated from Sporormiella australis, but its functional groups present a very high chemical reactivity which is responsible for its limited use [17]. A toxic metabolite of hydrolyzed fumonisin, AP1 and the fumonisin-related AAL-toxin are also potent CerS inhibitors [18].

\section{N-Acyl-Sphingosine Dehydrogenase or Dihydroceramide Desaturase}

The cyclopropene ceramide analog GT11 has been described as the first selective inhibitor of the dihydroceramide desaturase [19]. GT11 is a competitive inhibitor and its analogs with $\mathrm{N}$-hexanoyl and $\mathrm{N}$-decanoyl moieties inhibit the enzyme with similar effects [20]; differently urea and 
thiourea analogs have significantly lower effect [21]. A new inhibitor of this enzyme is XM462 which reduces the viability in Jukat A3 cells cultured in serum-free medium [22].

\section{Cytidyldiphosphocholine Transferase}

The cAMP analogs as chlorophenylthio-cAMP reduce strongly CTP: phosphocholine cytidylyltransferase activity in cultured rat hepatocytes [23]. In HaCaT cells this enzyme is inhibited by sphingomyelin analogs as acetyl-erythrosphingosine-1-phosphocholine and N-octanoyl-erythrosphingosine-1-phosphocholine [24] whereas reversible inhibitors are sphingosine and lysosphingolipids [25].

\section{Sphingomyelin Synthase (SMS)}

In U937 human monocytic leukemia cells, SMS is inhibited by tricyclodecan-9-yl-xanthogenate [26] but its pivaloyloxymethyl analog results more potent [27]. Also MS-209, a quinolone-derivative, has been described as a SMS inhibitor [28]. In addition, the products of SM metabolism, ceramide and sphingosine, inhibit SMS restoring the homeostasis between SM and ceramide pools [29].

\section{INHIBITORS OF SPHINGOMYELIN UTILIZATION}

The existence of different kinds of sphingomyelinase (SMase) has been widely described [30]. The $\mathrm{Mg}^{++}$dependent, membrane-associated, neutral SMase (N-SMase) is inhibited, in a dose-dependent manner, by glutathione at physiological concentrations [31]. An active compound which inhibits N-SMase, scyphostatin, has been extracted from a discomycete, Trichopeziza mollissima SANK 13892 [32]. This inhibitor determines a 50\% inhibition of N-SMase at the concentration value of $1.0 \mathrm{microM}$ whereas to inhibit lysosomal aSMase approximately 50 -fold greater concentration is required [33]. Scyphostatin, inhibiting N-SMase, prevents downstream of mitogen-activated protein kinases [34]. Also scyphostatin analogs $3 a$ and $3 b$ have inhibitor effects on N-SMase; in particular the primary hydroxy group in compound 2 is important for this activity [35]. Scyphostatin analog 14 , a chemically and metabolically stabilized compound lacking the epoxy function of the natural congener and carrying a palmitic acid group instead of the native trienoyl residue induces N-SMase inhibition in several systems (monocytes, macrophages, hepatocytes) [36]. Chlorogentisylquinone, purified from the culture broth of a fungal strain FOM-8108 isolated from a marine environment by solvent extraction, silica gel chromatography and Sephadex LH-20 chromatography, inhibits N-SMase rat brain membranes [37]. One inhibitor discovered in the screening on $\mathrm{N}$ SMase, GW4869, functions as a noncompetitive inhibitor of the N-SMase in vitro but it does not inhibit aSMase [38]. An irreversible specific inhibitor of $\mathrm{N}$-SMase is manumycin A [39] whereas competitive inhibitors have been extracted from Abies nephrolepis, Acer tegmentosum, and Ginkgo biloba [40]. A SM methylene analog, synthesized by Hofmann rearrangement of the alpha-hydroxyethyl-betahydroxy amide 4 followed by the intramolecular oxazolidinone ring formation as the key steps, has been designed as a $\mathrm{N}$-SMase inhibitor [41]. Also SM nitrogen analog 1 synthesized by continuous Hofmann and Crutius rearrangement as key steps in constructing the 3-hydroxy-1,2-diamine structure in the backbone of 1 has SMase inhibitor effect [42]. In
PC-12 neurons another analog of SM, difluoromethylene, inhibits N-SMase activity [43]. Short-chain analogs of Npalmitoylsphingosine-1-phosphate are non-competitive inhibitors with the same level of inhibitory activity of schyphostatin [44]. N-SMase inhibitor, undecylidene aminoguanidine C11AG, blocks lipopolysaccharide-stimulated SM degradation and NF kappa B activation [45]. SR33557, an aSMase inhibitor, counteracts TNF-alpha-mediated effect of IL-1beta-induced NF-kappaB activation [46]. Nitric oxide/cyclic guanosine 3',5'-monophosphate pathway inhibits aSMase in a mouse model of lipopolysaccharide-induced sepsis [47] whereas desipramine induces proteolytic degradation of aSMase [48].

\section{INHIBITORS OF CERAMIDE UTILIZATION}

The ceramide new-synthesized or derived from SM metabolism can be phosphorylated, glycosylated to form glucosylceramide and galactocerebroside or degraded to sphingosine which can be phosphorylated by sphingosine-1-kinase (SphK1). Many enzymes are involved in this metabolism and different inhibitors have been described. The ceramide kinase (CerK) is inhibited specifically by a novel F-12509A olefin isomer, $\mathrm{K} 1$, which does not act on sphingosine kinase and diacylglycerol kinase [49]. N-butyldeoxynojirimycin and N-butyldeoxygalactonojirimycin, synthetic analogs of the iminosugars, polyhydroxypiperidine alkaloid deoxynojirimycin, have inhibitory activity against the glucosyl ceramide synthase (GCerS) [50,51]. Also $N$-nonyldeoxynojirimycin [52] and the imino sugar OGT2378 [53] show effects on GCerS in different cell studies. D-threo-1-phenyl-2benzyloxycarbonylamino-3-pyrrolidino-1-pr opanol is the most potent inhibitor [54]. 1-phenyl-2-decanoylamino-3morpholino-1-propanol inhibits the human GCerS, but not the same enzyme present in other organisms [55]. SR33557 inhibitor consists of four isomers and only D-threo is the active form on murine GCerS [56]. Moreover some isofagomine analogues of the alkaloid fagomine bearing an alkyl chain on the C6 position [57]. $\mathrm{N}$-acyl derivatives of valienamine lack inhibitory activity, while the corresponding $\mathrm{N}$-alkyl analogs are very strong GCerS inhibitors; the $\mathrm{N}$-octyl derivative of valienamine is the most potent of the series [58]. The inhibition of glucosylceramidase (GCase) has been obtained by 1-phenyl-2-decanoylamino-3-morpholino-1-propanol (PDMP) and 1-phenyl-2-hexadecanoylamino-3-pyrrolidino-1-propanol [59]. The acid ceramidase (AC) activity present in human $\mathrm{HaCaT}$ keratinocytes and human melanoma cells is suppressed by ceramide analogs $(1 \mathrm{~S}, 2 \mathrm{R})-2-\mathrm{N}$-myristoylamino-1-phenyl-1-propanol and $(1 \mathrm{R}, 2 \mathrm{R})$ 2-N-myristoylamino-1-(4-nitrophenyl)-1,3-propan-diol [60]. Also desipramine induces a time- and dose-dependent down regulation of AC [61] whereas D-erythro-(1R,2R)-2-Nmyristoylamino-1-(4-nitrophenyl)-1,3 propandiol is used as inhibitor of neutral ceramidase (NC) [62]. The new inhibitor of AC is LCL204 which in DU145 PCa cells induces a reduction of sphingosine and an increase of ceramide level [63]. Compounds extracted from fungi as sphingosine derivatives, DL-threo-dihydrosphingosine and dimethylsphingosine, inhibit the SphK1 activity [64]. The inhibition of basal SphK1 activity is obtained by N,N-dimethylsphingosine [65]. DL-threo-dihydrosphingosine, besides SphK1 inhibition, increases the sensitivity of HEK-293 cells to fumonisin B1, inhibitor of CerS [66]. While N,N-dimethyl- 
sphingosine displays inhibitory effects for both SphK1 and SphK2, synthetic sphingoid analogs, as SG12 and SG14, have specific inhibitory effects on SphK2 [67].

\section{ROLE ON CELL FUNCTION}

Sphingolipid metabolism produces second messengers as ceramide, sphingosine and sphingosine-1-phosphate which have different functions in cell life. For instance, while ceramide can mediate and induce cell death, sphingosine-1phosphate results to be a second messenger for cell survival and proliferation and protection against ceramide mediated apoptosis [68-70]. Sphingolipid metabolites are interconvertible, it is not the individual quantitative level to determine cell fate, but their relative levels [71]. This observation has brought some researchers to propose the "rheostat ceramide/ sphingosine-1-phosphate" model indicating that an equilibrium between these two molecules is crucial to determine a cell survival or death [72] In addition, the biological effects of all sphingolipid metabolites may vary according to cell type, depending on the extracellular stimulus, on the relation between the different metabolite concentrations and the involved subcellular compartment, on cell cycle phase and on cell development [73-75]. The regulation of sphingolipid metabolites depends on their specific enzyme activity and therefore, the enzyme inhibitors are able to modify cell function (Fig. 1).

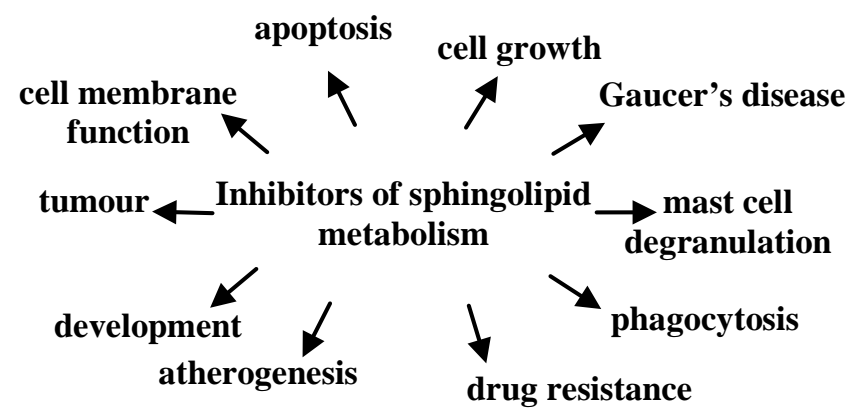

Fig. (1). Sphingolipid metabolism inhibitors in physiological and pathological processes.

\section{Apoptosis and Cell Growth}

Apoptosis is modified by myriocin which, by acting on SPT, interferes with the early steps of CD95-mediated caspase activation inducing the block of activation-induced cell death in T-cell hybridomas and T-cell blasts [76]. Also tricyclodecan-9-yl-xanthogenate, by inhibiting SMS, induces apoptosis in U937 human monocytic leukemia cells [77] such as Fumonisin B1, by inhibiting CerS, regulates serum deprivation-induced cell death in LLC-PK1 cells [78]. Moreover Fumonisin B1 abrogates the proapoptotic effects of palmitate on L6 myotubes [78]. Inhibition of basal SphK1 activity, obtained by $\mathrm{N}, \mathrm{N}$-dimethylsphingosine, induces a spontaneous apoptosis in A549 carcinoma cells [66]. In contrast to pro-survival $\mathrm{SphK} 1$, the protein $\mathrm{SphK} 2$, a nuclear protein [79], inhibits cell growth and enhances apoptosis [80]. In fact the suppression by small interfering RNA treatment prevents serum deprivation- or drug-induced apoptosis in HEK293 cells [81]. Three multidrug-resistant KB cell lines, KB-C1, KB-A1 and KB-V1 are induced to apoptosis preferentially respect to the drug-sensitive cell lines by two inhibitors of GCase, PDMP and 1-phenyl-2-hexadecanoyl- amino-3-pyrrolidino-1-propanol [60]. Difluoromethylene analog of SM inhibits N-SMase activity in bovine brain microsomes suppressing TNF-induced apoptosis of PC-12 neurons at a low concentration [44]. In the same cells, nine difluoromethylene analogues of SM suppress cell death induced by serum deprivation [82]. In Jurkat T-cell lymphoma cells, treatment with C11AG, by inhibiting N-SMase, enhances the sensitivity to apoptosis [46]. SR33557, an aSMase inhibitor, avoids apoptosis induced by TNF in ML-1a cells [83]. Treatment with D-threo- PDMP, but not with another GCerS inhibitor, N-butyldeoxynojirimycin, results in a dose-dependent reduction of the growth rate [84]. D-threo-1phenyl-2-decanoylamino-3-morpholino-1-propanol inhibits NGF-induced neurite outgrowth of PC12 cells [85]. Differently GT11, by inhibiting dihydroceramide desaturase, has cell protective properties in primary cultured cerebellar neurons [86].

\section{Development}

PDMP, by inhibiting glucosphingolipid synthesis, triggers oocyte meiotic maturation representing an important regulator of oocyte meiosis [87]. Moreover PDMP-treated fish embryos are fully viable with no evidence of developmental abnormality [88].

\section{Membrane Structure and Function}

Chloroalanine, inhibitor of SPT, has been used to investigate the role of skin sphingosine synthesis inhibition in the permeation of levodopa, a hydrophilic drug, across rat skin [89]. Moreover beta- chloroalanine causes paradoxical effects on barrier permeability homeostasis [90] and delays mammalian epidermal barrier recovery after acute perturbation [91]. In essential fatty acid deficient mice, with a chronic disturbance in barrier function, beta-chloroalanine impairs recovery of barrier structure and function [92].

\section{Tumor Process and Drug Resistance}

The iminosugar OGT2378, inhibitors of GCerS, is used to reduce tumorigenic capability of MEB4 melanoma cells [54]. D-threo- PDMP exhibits anti-tumor activity against two different Shope carcinoma cell lines [93]. Both threo and erythro racemic compounds of SR33557, an aSMase inhibitor, induces a strong inhibition of human cancer cell growth [94]. Moreover GCerS inhibition by 1-phenyl-2-hexadecanoylamino-3-pyrrolidino-1-propanol enhances tumor cell sensitivity to vincristine [95]. 1-phenyl-2-hexadecanoyl amino-3-pyrrolidino-1-propanol and PDMP enhance doxoru bicin-elicited ceramide elevation in HepG2 hepatoma cells but only the second inhibitor potentiates the modest apoptotic response to doxorubicin treatment [96]. The GCase inhibition has been implicated in drug resistance; in fact in the absence of functional Gcase, melanoma cells do not respond to anticancer drugs [97].

\section{Other Functions}

The inhibition of CerK is responsible for mast cell degranulation [50]. L-cycloserine, by inhibiting SPT, enhances phagocytosis in COS-1 cells [98]. Reducing the ceramide content, myriocin is responsible for the decrease of SM concentration in the liver [12] accompanied by a decrease of total cholesterol and triglyceride plasma levels and of atherosclerotic lesions demonstrating that inhibition of SM synthesis reduces atherogenesis [12]. 
N-butyldeoxynojirimycin and the imino sugar OGT2378, inhibitors of GCerS, are used in therapy for treating type I Gaucher disease [99]. Treatment with D-threo PDMP, but not with another GCerS inhibitor, causes cell death in NG108-15 cells, suggesting that this inhibitor is toxic for treatment of Gaucher's disease [85]. In chinese hamster ovary cells it induces lysosomes vacuolization [100].

\section{CONCLUSIONS}

In the last ten years the definition of "fundamental structural components of biological membranes" has become reductive for the sphingolipids. In fact, this class of lipids constitutes a source of bioactive molecules which, together with the enzymes of the sphingolipid metabolism, are involved in signal transduction and in some fundamental cellular mechanisms as proliferation and its arrest, differentiation and apoptosis, embryogenesis and ageing regulation. Different inhibitors of the sphingolipid metabolism are able to block the synthesis and/or utilization of the sphingolipids at various levels regulating the metabolite molecule concentrations. The direct consequence is the modification of cell proliferation, differentiation and/or apoptosis lipid-induced. Therefore inhibitors of sphingolipid metabolism enzymes could be used to regulate cell function in physiological and pathological conditions.

\section{ABBREVIATIONS}

$\begin{array}{ll}\text { AC } & =\text { Acid ceramidase } \\ \text { aSMase } & =\text { Acid sphingomyelinase } \\ \text { CerK } & =\text { Ceramide kinase } \\ \text { CerS } & =\text { Ceramide synthase } \\ \text { GCase } & =\text { Glucosyl ceramidase } \\ \text { GCerS } & =\text { Glucosyl ceramide synthase } \\ \text { NC } & =\text { Neutral ceramidase } \\ \text { N-SMase } & =\text { Neutral sphingomyelinase } \\ \text { PDMP } & =1 \text {-Phenyl-2-decanoylamino-3-morpholino- } \\ \text { PPPP } & =1 \text {-Phopanol } \\ \text { SM } & =\text { Sphingomyelin } \\ \text { SMS } & =\text { Sphingomyelin-synthase } \\ \text { SphK1 } & =\text { Sphingosine kinase 1 } \\ \text { SphK2 } & =\text { Sphingosine Kinase 2 } \\ \text { SPT } & =\text { Serine palmitoyl transferase } \\ \text { ACKNOWLEDGEMENTS }\end{array}$

We wish to acknowledge support from Ministero dell' Università e Ricerca (PRIN project), ASI (Agenzia Spaziale Italiana), and the Fondazione Cassa di Risparmio di Perugia. We also thank Dr. Ilaria Bernardini, and Remo Lazzarini for the discussion and Silvano Pagnotta for the figure preparation.

\section{REFERENCES}

[1] Gupta BS, Tiwary AK. Role of sphingosine synthesis inhibition in transcutaneous delivery of levodopa. Int J Pharm 2002; 238(1-2): $43-50$.
Wang H, Giuliano AE, Cabot MC. Enhanced de novo ceramide generation through activation of serine palmitoyltransferase by the P-glycoprotein antagonist SDZ PSC 833 in breast cancer cells. Mol Cancer Ther 2002; 1(9): 719-26.

van Echten-Deckert G, Schick A, Heinemann T, Schnieders B. Phosphorylated cis-4-methylsphingosine mimics the mitogenic effect of sphingosine-1-phosphate in Swiss 3T3 fibroblasts. J Biol Chem 1998; 273(36): 23585-9.

Hanada K. Serine palmitoyltransferase, a key enzyme of sphingolipid metabolism. Biochim Biophys Acta 2003; 1632(1-3): 16-30. Zweerink MM, Edison AM, Wells GB, Pinto W, Lester RL. Characterization of a novel, potent, and specific inhibitor of serine palmitoyltransferase. J Biol Chem 1992; 267(35): 25032-8.

Fujita T, Inoue K, Yamamoto S, et al. Fungal metabolites. Part 11. A potent immunosuppressive activity found in Isaria sinclairii metabolite. J Antibiot (Tokyo) 1994; 47(2): 208-15.

Fujita T, Inoue K, Yamamoto S, et al. Fungal metabolites. Part 12. Potent immunosuppressant, 14-deoxomyriocin, (2S,3R,4R)-(E)-2amino-3,4-dihydroxy-2-hydroxymethyleicos-6-enoic acid and structure-activity relationships of myriocin derivatives. J Antibiot (Tokyo) 1994; 47(2): 216-24.

Fujita T, Hamamichi N, Kiuchi M, et al. Determination of absolute configuration and biological activity of new immunosuppressants, mycestericins D, E, F and G. J Antibiot (Tokyo) 1996; 49(9): 84653.

Gupta M, Mahajan A, Babita, Gupta S, Tiwary AK. Inhibition of skin sphingosine synthesis: Enhanced percutaneous permeation of 5-fluorouracil. Pharmazie 2004; 59(3): 212-6.

Kroesen BJ, Jacobs S, Pettus BJ, et al. BcR-induced apoptosis involves differential regulation of $\mathrm{C} 16$ and $\mathrm{C} 24$-ceramide formation and sphingolipid-dependent activation of the proteasome. J Biol Chem 2003; 278(17): 14723-31.

Park TS, Panek RL, Mueller SB, et al. Inhibition of sphingomyelin synthesis reduces atherogenesis in apolipoprotein E-knockout mice. Circulation 2004; 110(22): 3465-71.

Chalfant CE, Ogretmen B, Galadari S, Kroesen BJ, Pettus BJ, Hannun YA. FAS activation induces dephosphorylation of SR proteins: Dependence on the de novo generation of ceramide and activation of protein phosphatase 1. J Biol Chem 2001; 276(48): 44848-55.

Gopee NV, Sharma RP. The mycotoxin fumonisin B1 transiently activates nuclear factor-kappaB, tumor necrosis factor alpha and caspase 3 via protein kinase Calpha-dependent pathway in porcine renal epithelial cells. Cell Biol Toxicol 2004; 20(4): 197-212.

Desai K, Sullards MC, Allegood J, et al. Fumonisins and fumonisin analogs as inhibitors of ceramide synthase and inducers of apoptosis. Biochim Biophys Acta 2002; 1585(2-3): 188-92.

Rentz SS, Showker JL, Meredith FI, Riley RT. Inhibition of sphingolipid biosynthesis decreases phosphorylated ERK2 in LLC-PK1 cells. Food Chem Toxicol 2005; 43(1): 123-31.

He Q, Suzuki H, Sharma N, Sharma RP. Ceramide synthase inhibition by fumonisin B1 treatment activates sphingolipid-metabolizing systems in mouse liver. Toxicol Sci 2006; 94(2): 388-97.

Mandala SM, Thornton RA, Frommer BR, et al. The discovery of australifungin, a novel inhibitor of sphinganine $\mathrm{N}$-acyltransferase from Sporormiella australis. Producing organism, fermentation, isolation, and biological activity. J Antibiot (Tokyo) 1995; 48(5): 349-56.

Humpf HU, Schmelz EM, Meredith FI, et al. Acylation of naturally occurring and synthetic 1-deoxysphinganines by ceramide synthase. Formation of N-palmitoyl-aminopentol produces a toxic metabolite of hydrolyzed fumonisin, AP1, and a new category of ceramide synthase inhibitor. J Biol Chem 1998; 273(30): 19060-4. Triola G, Fabrias G, Llebaria A. Synthesis of a cyclopropene analogue of ceramide, a potent inhibitor of dihydroceramide desaturase. Angew Chem Int Ed Eng1 2001; 40(10): 1960-1962.

Triola G, Fabrias G, Casas J, Llebaria A. Synthesis of cyclopropene analogues of ceramide and their effect on dihydroceramide desaturase. J Org Chem 2003; 68(26): 9924-32.

Bedia C, Triola G, Casas J, Llebaria A, Fabrias G. Analogs of the dihydroceramide desaturase inhibitor GT11 modified at the amide function: Synthesis and biological activities. Org Biomol Chem 2005; 3(20): 3707-12.

Munoz-Olaya JM, Matabosch X, Bedia C, et al. Synthesis and biological activity of a novel inhibitor of dihydroceramide desaturase. Chem Med Chem 2008; 3(6): 946-53. 
[23] Pelech SL, Pritchard PH, Vance DE. cAMP analogues inhibit phosphatidylcholine biosynthesis in cultured rat hepatocytes. J Biol Chem 1981; 256(16): 8283-6.

[24] Wieder T, Perlitz C, Wieprecht M, Huang RT, Geilen CC, Orfanos CE. Two new sphingomyelin analogues inhibit phosphatidylcholine biosynthesis by decreasing membrane-bound CTP: Phosphocholine cytidylyltransferase levels in HaCaT cells. Biochem $\mathbf{J}$ 1995; 311 ( Pt 3): 873-9.

[25] Sohal PS, Cornell RB. Sphingosine inhibits the activity of rat liver CTP: Phosphocholine cytidylyltransferase. J Biol Chem 1990; 265 (20): 11746-50.

[26] Meng A, Luberto C, Meier P, et al. Sphingomyelin synthase as a potential target for D609-induced apoptosis in U937 human monocytic leukemia cells. Exp Cell Res 2004; 292(2): 385-92.

[27] Wenk MR. The emerging field of lipidomics. Nat Rev Drug Discov 2005; 4(7): 594-610.

[28] Robert J. MS-209 Schering. Curr Opin Investig Drugs 2004; 5(12): 1340-7.

[29] Vivekananda J, Smith D, King RJ. Sphingomyelin metabolites inhibit sphingomyelin synthase and CTP: Phosphocholine cytidylyltransferase. Am J Physiol Lung Cell Mol Physiol 2001; 281(1): L98-L107.

[30] Albi E, Cataldi S, Bartoccini E, et al. Nuclear sphingomyelin pathway in serum deprivation-induced apoptosis of embryonic hippocampal cells. J Cell Physiol 2006; 206(1): 189-95.

[31] Liu B, Hannun YA. Inhibition of the neutral magnesiumdependent sphingomyelinase by glutathione. J Biol Chem 1997; 272(26): 16281-7.

[32] Nara F, Tanaka M, Hosoya T, Suzuki-Konagai K, Ogita T. Scyphostatin, a neutral sphingomyelinase inhibitor from a discomycete, Trichopeziza mollissima: Taxonomy of the producing organism, fermentation, isolation, and physico-chemical properties. $\mathrm{J}$ Antibiot (Tokyo) 1999; 52(6): 525-30.

[33] Nara F, Tanaka M, Masuda-Inoue S, et al. Biological activities of scyphostatin, a neutral sphingomyelinase inhibitor from a discomycete, Trichopeziza mollissima. J Antibiot (Tokyo) 1999; 52(6): 531-5.

[34] Czarny M, Schnitzer JE. Neutral sphingomyelinase inhibitor scyphostatin prevents and ceramide mimics mechanotransduction in vascular endothelium. Am J Physiol Heart Circ Physiol 2004; 287 (3): H1344-52.

[35] Arenz C, Thutewohl M, Block O, Waldmann H, Altenbach HJ, Giannis A. Manumycin A and its analogues are irreversible inhibitors of neutral sphingomyelinase. Chembiochem 2001; 2(2): 1413.

[36] Claus RA, Wustholz A, Muller S, et al. Synthesis and antiapoptotic activity of a novel analogue of the neutral sphingomyelinase inhibitor scyphostatin. Chembiochem 2005; 6(4): 726-37.

[37] Uchida R, Tomoda H, Arai M, Omura S. Chlorogentisylquinone, a new neutral sphingomyelinase inhibitor, produced by a marine fungus. J Antibiot (Tokyo) 2001; 54(11): 882-9.

[38] Luberto C, Hassler DF, Signorelli P, et al. Inhibition of tumor necrosis factor-induced cell death in MCF7 by a novel inhibitor of neutral sphingomyelinase. J Biol Chem 2002; 277(43): 41128-39.

[39] Arenz C, Gartner M, Wascholowski V, Giannis A. Synthesis and biochemical investigation of scyphostatin analogues as inhibitors of neutral sphingomyelinase. Bioorg Med Chem 2001; 9(11): 2901-4.

[40] Kim SK, Jung SM, Ahn KH, et al. Identification of three competitive inhibitors for membrane-associated, $\mathrm{Mg} 2+$-dependent and neutral $60 \mathrm{kDa}$ sphingomyelinase activity. Arch Pharm Res 2005; 28(8): 923-9.

[41] Hakogi T, Monden Y, Iwama S, Katsumura S. Stereocontrolled synthesis of a sphingomyelin methylene analogue as a sphingomyelinase inhibitor. Org Lett 2000; 2(17): 2627-9.

[42] Hakogi T, Taichi M, Katsumura S. Synthesis of a nitrogen analogue of sphingomyelin as a sphingomyelinase inhibitor. Org Lett 2003; 5(16): 2801-4.

[43] Yokomatsu T, Takechi H, Akiyama T, et al. Synthesis and evaluation of a difluoromethylene analogue of sphingomyelin as an inhibitor of sphingomyelinase. Bioorg Med Chem Lett 2001; 11(10): 1277-80.

[44] Yokomatsu T, Murano T, Akiyama T, et al. Synthesis of noncompetitive inhibitors of sphingomyelinases with significant activity. Bioorg Med Chem Lett 2003; 13(2): 229-36.
[45] Amtmann E, Baader W, Zoller M. Neutral sphingomyelinase inhibitor C11AG prevents lipopolysaccharide-induced macrophage activation. Drugs Exp Clin Res 2003; 29(1): 5-13.

[46] Amtmann E, Zoller M. Stimulation of CD95-induced apoptosis in T-cells by a subtype specific neutral sphingomyelinase inhibitor. Biochem Pharmacol 2005; 69(8): 1141-8.

[47] Saldeen J, Jaffrezou JP, Welsh N. The acid sphingomyelinase inhibitor SR33557 counteracts TNF-alpha-mediated potentiation of IL-1beta-induced NF-kappaB activation in the insulinproducing cell line Rinm5F. Autoimmunity 2000; 32(4): 241-54.

[48] Falcone S, Perrotta C, De Palma C, et al. Activation of acid sphingomyelinase and its inhibition by the nitric oxide/cyclic guanosine 3',5'-monophosphate pathway: Key events in Escherichia colielicited apoptosis of dendritic cells. J Immunol 2004; 173(7): 4452-63.

[49] Hurwitz R, Ferlinz K, Sandhoff K. The tricyclic antidepressant desipramine causes proteolytic degradation of lysosomal sphingomyelinase in human fibroblasts. Biol Chem Hoppe Seyler 1994; 375(7): 447-50.

[50] Kim JW, Inagaki Y, Mitsutake S, et al. Suppression of mast cell degranulation by a novel ceramide kinase inhibitor, the F-12509A olefin isomer K1. Biochim Biophys Acta 2005; 1738(1-3): 82-90.

[51] Platt FM, Neises GR, Dwek RA, Butters TD. N-butyldeoxynojirimycin is a novel inhibitor of glycolipid biosynthesis. J Biol Chem 1994; 269(11): 8362-5.

[52] Platt FM, Neises GR, Karlsson GB, Dwek RA, Butters TD. Nbutyldeoxygalactonojirimycin inhibits glycolipid biosynthesis but does not affect $\mathrm{N}$-linked oligosaccharide processing. J Biol Chem 1994; 269(43): 27108-14.

[53] Sawkar AR, Cheng WC, Beutler E, Wong CH, Balch WE, Kelly JW. Chemical chaperones increase the cellular activity of N370S beta -glucosidase: A therapeutic strategy for Gaucher disease. Proc Natl Acad Sci USA 2002; 99(24): 15428-33.

[54] Weiss M, Hettmer S, Smith P, Ladisch S. Inhibition of melanoma tumor growth by a novel inhibitor of glucosylceramide synthase. Cancer Res 2003; 63(13): 3654-8.

[55] Jimbo M, Yamagishi K, Yamaki T, et al. Development of a new inhibitor of glucosylceramide synthase. J Biochem 2000; 127(3): 485-91.

[56] Hillig I, Warnecke D, Heinz E. An inhibitor of glucosylceramide synthase inhibits the human enzyme, but not enzymes from other organisms. Biosci Biotechnol Biochem 2005; 69(9): 1782-5.

[57] Inokuchi J, Radin NS. Preparation of the active isomer of 1-phenyl2-decanoylamino-3-morpholino-1-propanol, inhibitor of murine glucocerebroside synthetase. J Lipid Res 1987; 28(5): 565-71.

[58] Fan J, Zhu X, Shet K. US 2005/0130972 A1. 2005 June. 16.

[59] Ogawa S, Kobayashi Y, Kabayama K, Jimbo M, Inokuchi J. Chemical modification of beta-glucocerebrosidase inhibitor $\mathrm{N}$ octyl-beta-valienamine: Synthesis and biological evaluation of $\mathrm{N}$ alkanoyl and N-alkyl derivatives. Bioorg Med Chem 1998; 6(10): 1955-62

[60] Nicholson KM, Quinn DM, Kellett GL, Warr JR. Preferential killing of multidrug-resistant KB cells by inhibitors of glucosylceramide synthase. Br J Cancer 1999; 81(3): 423-30

[61] Raisova M, Goltz G, Bektas M, et al. Bcl-2 overexpression prevents apoptosis induced by ceramidase inhibitors in malignant melanoma and HaCaT keratinocytes. FEBS Lett 2002; 516(1-3): 47-52.

[62] Elojeimy S, Holman DH, Liu X, et al. New insights on the use of desipramine as an inhibitor for acid ceramidase. FEBS Lett 2006; 580(19): 4751-6.

[63] Choi MS, Anderson MA, Zhang Z, Zimonjic DB, Popescu N, Mukherjee AB. Neutral ceramidase gene: role in regulating ceramide-induced apoptosis. Gene 2003; 315: 113-22.

[64] Holman DH, Turner LS, El-Zawahry A, et al. Lysosomotropic acid ceramidase inhibitor induces apoptosis in prostate cancer cells. Cancer Chemother Pharmacol 2008; 61(2): 231-42.

[65] Nagiec MM, Nagiec EE, Baltisberger JA, Wells GB, Lester RL, Dickson RC. Sphingolipid synthesis as a target for antifungal drugs. Complementation of the inositol phosphorylceramide synthase defect in a mutant strain of Saccharomyces cerevisiae by the AUR1 gene. J Biol Chem 1997; 272(15): 9809-17.

[66] Billich A, Bornancin F, Mechtcheriakova D, Natt F, Huesken D, Baumruker T. Basal and induced sphingosine kinase 1 activity in A549 carcinoma cells: function in cell survival and IL-1beta and 
TNF-alpha induced production of inflammatory mediators. Cell Signal 2005; 17(10): 1203-17.

[67] Kim JW, Kim YW, Inagaki Y, et al. Synthesis and evaluation of sphingoid analogs as inhibitors of sphingosine kinases. Bioorg Med Chem 2005; 13(10): 3475-85.

[68] Sharma N, He Q, Sharma RP. Sphingosine kinase activity confers resistance to apoptosis by fumonisin B1 in human embryonic kidney (HEK-293) cells. Chem Biol Interact 2004; 151(1): 33-42.

[69] Maceyka M, Milstien S, Spiegel S. Sphingosine kinases, sphingosine-1-phosphate and sphingolipidomics. Prostaglandins Other Lipid Mediat 2005; 77(1-4): 15-22.

[70] Kolesnick R. The therapeutic potential of modulating the ceramide/sphingomyelin pathway. J Clin Invest 2002; 110(1): 3-8.

[71] Spiegel S, Milstien S. Exogenous and intracellularly generated sphingosine 1-phosphate can regulate cellular processes by divergent pathways. Biochem Soc Trans 2003; 31(Pt 6): 1216-9.

[72] Cuvillier O. Sphingosine in apoptosis signaling. Biochim Biophys Acta 2002; 1585(2-3): 153-62.

[73] Luberto C, Kraveka JM, Hannun YA. Ceramide regulation of apoptosis versus differentiation: A walk on a fine line. Neurochem Res 2002, 27: 609-17.

[74] Mitoma J, Ito M, Furuya S, Hirabayashi Y. Bipotential roles of ceramide in the growth of hippocampal neurons: Promotion of cell survival and dendritic outgrowth in dose- and developmental stage-dependent manners. J Neurosci Res 1998; 51(6): 712-22.

[75] Tomassini B, Testi R. Mitochondria as sensors of sphingolipids. Biochimie 2002; 84(2-3): 123-9.

[76] Solomon JC, Sharma K, Wei LX, Fujita T, Shi YF. A novel role for sphingolipid intermediates in activation-induced cell death in $\mathrm{T}$ cells. Cell Death Differ 2003; 10(2): 193-202.

[77] Yu MU, Yoo JM, Lee YS, et al. Altered de novo sphingolipid biosynthesis is involved in the serum deprivation-induced cell death in LLC-PK1 cells. J Toxicol Environ Health A 2004; 67(2324): 2085-94.

[78] Turpin SM, Lancaster GI, Darby I, Febbraio MA, Watt MJ. Apoptosis in skeletal muscle myotubes is induced by ceramides and is positively related to insulin resistance. Am J Physiol Endocrinol Metab 2006; 291(6): E1341-50.

[79] Igarashi N, Okada T, Hayashi S, Fujita T, Jahangeer S, Nakamura $\mathrm{S}$. Sphingosine kinase 2 is a nuclear protein and inhibits DNA synthesis. J Biol Chem 2003; 278(47): 46832-9.

[80] Maceyka M, Sankala H, Hait NC, et al. SphK1 and SphK2, sphingosine kinase isoenzymes with opposing functions in sphingolipid metabolism. J Biol Chem 2005; 280(44): 37118-29.

[81] Okada T, Ding G, Sonoda H, et al. Involvement of N-terminalextended form of sphingosine kinase 2 in serum-dependent regulation of cell proliferation and apoptosis. J Biol Chem 2005; 280(43): 36318-25.

[82] Tsuji Y, Soeda S, Ochiai T, et al. Synthesis of sphingomyelin analogues as a sphingomyelinase inhibitor and the application as a blocking agent of extracellular stress signaling. Nippon Yakurigaku Zasshi 2002; 120(1): 67P-69P.

[83] Jaffrezou JP, Herbert JM, Levade T, Gau MN, Chatelain P, Laurent $\mathrm{G}$. Reversal of multidrug resistance by calcium channel bloc- ker SR33557 without photoaffinity labeling of P-glycoprotein. J Biol Chem 1991; 266(29): 19858-60.

[84] Bieberich E, Freischutz B, Suzuki M, Yu RK. Differential effects of glycolipid biosynthesis inhibitors on ceramide-induced cell death in neuroblastoma cells. J Neurochem 1999; 72(3): 1040-9.

[85] Mutoh T, Tokuda A, Inokuchi J, Kuriyama M. Glucosylceramide synthase inhibitor inhibits the action of nerve growth factor in PC12 cells. J Biol Chem 1998; 273(40): 26001-7.

[86] Triola G, Fabrias G, Dragusin M, et al. Specificity of the dihydroceramide desaturase inhibitor $\mathrm{N}-[(1 \mathrm{R}, 2 \mathrm{~S})-2$-hydroxy-1-hydroxymethyl-2-(2-tridecyl-1-cyclopropenyl)ethyl]o ctanamide (GT11) in primary cultured cerebellar neurons. Mol Pharmacol 2004; 66(6): 1671-8.

[87] De Smedt V, Rime H, Jessus C, Ozon R. Inhibition of glycosphingolipid synthesis induces p34cdc2 activation in Xenopus oocyte. FEBS Lett 1995; 375(3): 249-53.

[88] Fenderson BA, Ostrander GK, Hausken Z, Radin NS, Hakomori S. A ceramide analogue (PDMP) inhibits glycolipid synthesis in fish embryos. Exp Cell Res 1992; 198(2): 362-6.

[89] Mao-Qiang M, Elias PM, Feingold KR. Fatty acids are required for epidermal permeability barrier function. J Clin Invest 1993; 92 (2): 791-8.

[90] Holleran WM, Feingold KR, Man MQ, Gao WN, Lee JM, Elias PM. Regulation of epidermal sphingolipid synthesis by permeability barrier function. J Lipid Res 1991; 32(7): 1151-8.

[91] Feingold KR. The regulation of epidermal lipid synthesis by permeability barrier requirements. Crit Rev Ther Drug Carrier Syst 1991; 8(3): 193-210.

[92] Hinkovska-Galcheva V, Boxer L, Mansfield PJ, Schreiber AD, Shayman JA. Enhanced phagocytosis through inhibition of de novo ceramide synthesis. J Biol Chem 2003; 278(2): 974-82.

[93] Kyogashima M, Inoue M, Seto A, Inokuchi J. Glucosylceramide synthetase inhibitor, D-threo-1-phenyl-2-decanoylamino-3-morpholino-1-propanol exhibits a novel decarcinogenic activity against Shope carcinoma cells. Cancer Lett 1996; 101(1): 25-30.

[94] Abe A, Radin NS, Shayman JA, et al. Structural and stereochemical studies of potent inhibitors of glucosylceramide synthase and tumor cell growth. J Lipid Res 1995; 36(3): 611-21.

[95] Olshefski RS, Ladisch S. Glucosylceramide synthase inhibition enhances vincristine-induced cytotoxicity. Int J Cancer 2001; 93 (1): 131-8.

[96] di Bartolomeo S, Spinedi A. Differential chemosensitizing effect of two glucosylceramide synthase inhibitors in hepatoma cells. Biochem Biophys Res Commun 2001; 288(1): 269-74.

[97] Veldman RJ, Mita A, Cuvillier O, et al. The absence of functional glucosylceramide synthase does not sensitize melanoma cells for anticancer drugs. FASEB J 2003; 17(9): 1144-6.

[98] Dougherty AM, McDonald FE, Liotta DC, et al. Synthesis of 1deoxysphingosine derivatives with conformationally restricted pyrrolidinediol head groups. Org Lett 2006; 8(4): 649-52.

[99] Cox TM. Substrate reduction therapy for lysosomal storage diseases. Acta Paediatr Suppl 2005; 94(447): 69-75; discussion 57.

[100] Rosenwald AG, Pagano RE. Effects of the glucosphingolipid synthesis inhibitor, PDMP, on lysosomes in cultured cells. J Lipid Res 1994; 35(7): 1232-40.

(C) Albi and Magni; Licensee Bentham Open.

This is an open access article licensed under the terms of the Creative Commons Attribution Non-Commercial License (http://creativecommons.org/licenses/by$\mathrm{nc} / 3.0 /$ ) which permits unrestricted, non-commercial use, distribution and reproduction in any medium, provided the work is properly cited. 